\title{
RIQUER I PERMANYER, Borja de Cambó en Argentina. Negocios y corrupción política, Edhasa, Barcelona, 2016, 574 pp. ISBN 978-84-350-2740-3.
}

\author{
Gabriela Dalla-Corte Caballero \\ Universitat de Barcelona, España \\ dallacorte@ub.edu
}

Al día de hoy, un buen número de historiadoras e historiadores reconocen las grandes actividades comerciales, culturales, políticas y empresariales efectuadas por el catalán Francesc Cambó durante la primera mitad del siglo XX. Sobre él, el historiador Borja de Riquer i Permanyer impulsó en los últimos años unos interesantes estudios sobre este personaje: L'Últim Cambó (1936-1947). La dreta catalanista davant la guerra civil i el primer franquisme; ${ }^{1}$ Francesc Cambó, home de negocis i empresari cultura; ${ }^{2}$ Francesc Cambó. Entre la Monarquia y la República; ${ }^{3}$ así como Alfonso XIII y Cambó. La monarquía y el catalanismo político. ${ }^{4}$ Especialista en historia catalana y española de los siglos XIX y XX, del catalanismo político y del franquismo, su último libro fue publicado como Anar de debò: el catalans i espanya, ${ }^{5}$ en el que trata la historia del nacionalismo catalán, y las relaciones mantenidas precisamente con España, como tema central del pasado y del presente político e historiográfico del país.

En esta oportunidad, Riquer acaba también de sacar a la luz un gran libro, de larga escritura, que lleva el nombre

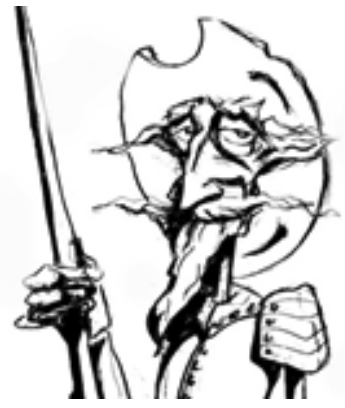
de Cambó en Argentina, obra que resulta imprescindible hoy día si pretendemos debatir la situación argentina, como país antiguamente colonizado, y que desde inicios del siglo XIX procuró conseguir no solo su independencia nacional, sino también la independencia productiva, comercial y de transportes, respecto a los grandes poderes europeos. En este marco de novedoso debate sobre la situación actual de la Argentina, Riquer i Permanyer nos aporta novedosas miradas con el subtítulo Negocios y corrupción política.

Esta obra es la que reseñamos aquí. Riquer comienza con su prólogo acerca de la historia oculta, y nada ejemplar, del personaje central Francesc Cambó, a quien lo define como fascinante, controvertido y poliédrico, pero prácticamente

\footnotetext{
${ }^{1}$ RIQUER I PERMANYER, Borja de L'Últim Cambó (1936-1947). La dreta catalanista davant la guerra civil i el primer franquisme, Grijalbo, Vic, 1996.

2 RIQUER I PERMANYER, Borja de Francesc Cambó, home de negocis i empresari cultural, Caixa Laietana, Mataró, 2005.

${ }^{3}$ RIQUER I PERMANYER, Borja de Francesc Cambó. Entre la Monarquia y la República, Editorial Base, Barcelona, 2007.

4 RIQUER I PERMANYER, Borja de Alfonso XIII y Cambó. La monarquía y el catalanismo político, RBA, Barcelona, 2013.

5 RIQUER I PERMANYER, Borja de Anar de debò: el catalans i espanya, Rosa dels Vents, Barcelona, 2016.
} 
desconocido, incluyendo el país donde nació, Cataluña, y donde murió, en la República Argentina. Con esta presentación el autor conmueve, por la realidad a la que nos hemos enfrentado todos aquellos que buscamos información sobre el catalán Cambó y la gran compañía de electricidad que dirigió en Buenos Aires; o para quienes también encontramos su presencia en otras actividades, muy importantes de la primera mitad del siglo $\mathrm{XX}$, como por ejemplo los dos instrumentos más internacionales que se volcaron a las novedosas relaciones con América: la Revista Comercial Iberoamericana Mercurio, por un lado, y la Casa de América de Barcelona, por el otro. Por ello me resulta trascendental describir la obra de Riquer, interesado desde hace años en analizar las relaciones gestadas entre Cataluña y Argentina de la mano de Cambó.

Como historiador, comienza con el análisis de la creación de la "Compañía Alemana Trasatlántica de Electricidad" (CATE), la mayor inversión alemana en el extranjero que exigiría a finales de la Primera Mundial un notorio cambio en el propio nombre de la empresa que pasó a llamarse "Compañía Hispano Argentina de Electricidad" (CHADE). Este hecho fue para mí un dato fundamental para comprender, a nivel personal e historiográfico, cómo se había preparado la nueva relación americanista. Esta opción no fue banal, ya que el grupo liderado por Cambó en plena guerra mundial, aparecía desde finales del siglo XIX como el más cercano al movimiento independentista, distanciado del ejercicio monárquico en las antiguas colonias americanas, de índole neoliberal, y con un sustancial término "iberoamericano", enfrentando así las palabras consideradas más españolas, como "hispanoamericana". El juego de estas palabras fue la base de transformación de la reciente inaugurada revista catalana Mercurio, cuando ya perdidas las islas de Cuba y Puerto Rico, también pasó en solo dos meses de llamarse Hispanoamérica a Iberoamericana. Estos personajes americanistas de Cataluña optaron por unirse años después a los "indianos" -aquellos españoles que salieron casi disparados de Cuba tras el triunfo del gobierno estadounidense contra la monarquía española-, con quienes comenzaron a hacer reuniones hasta alcanzar en abril de 1911 su entidad barcelonesa llamada Casa de América.

Fue este mismo grupo de estudiantes de derecho y de letras de la Universitat de Barcelona, entre ellos el propio Francesc Cambó que se graduó en las dos áreas de estudio, los que en 1919 asumieron la responsabilidad de transformar los objetivos de la revista Mercurio, y de cambiar los objetivos y la organización de la Casa de América de Barcelona, en virtud del fallecimiento del histórico director de ambas entidades, Frederic Rahola Trèmols. Rafael Vehils i GrauBolívar, el eterno secretario de Cambó en Barcelona y en Buenos Aires, escribió en ese año 1919 un documento titulado Banco Español Transatlántico, Sociedad Anónima en formación, fundamento, orientación, estructura. Las páginas demuestran el gran conocimiento que mantuvo Vehils en esos años para sostener los proyectos "visuales" (la revista Mercurio y la Casa de América), que en ese momento ya funcionaban en las dos propiedades de Frances Cambó 
ubicadas en la Vía Laietana, propiedades que hoy día están en manos de la familia Guardans-Cambó.

Gracias al fomento de la mundialización económica que hace Cambó, fue en esos años que la hermana de Rafael, María del Carmen Vehilsi Grau-Bolívar, se encargó de fundar y dirigir el Archivo más importante en la Casa de América a pedido de Cambó-, contratando a más de 25 mujeres cuya tarea era adquirir toda la prensa del mundo, y recortar los temas vinculados a la CHADE. Jefa del "Centro de Investigación Económica", María del Carmen se encargó de dirigir también el Archivo General de Economía (AGE) de la Casa de América, hasta su fallecimiento producido en la República Oriental del Uruguay.

El primer capítulo del libro de Borja de Riquer se centra en el traspaso de la gran empresa alemana CATE, a una supuesta unidad entre Argentina y España con la denominación CHADE. Por ello la documentación histórica utilizada por el autor es más que elocuente para dar respuesta al poder y al dinero que se jugaron en esa época. El segundo capítulo aborda las relaciones entre Cambó y Daniel Heineman, quienes precisamente efectuaron una original operación gracias a la visita que el primero hizo al segundo en Alemania, favoreciendo así a financieros y políticos españoles. El tercer capítulo se centra en la época de oro de la CHADE. Utilizando una variadísima documentación, puede afirmar que la mayoría de los accionistas no eran españoles y tenían sus acciones depositadas en bancos extranjeros, tanto suizos como belgas y británicos. El propio Cambó conservaba sus fondos económicos personales en la banca suiza. Y reproduce un documento donde aparecen los decretos del gobierno español que ayudaron sin duda a la CHADE entre 1924 y los inicios de la Guerra Civil española. En esa década participó activamente el propio General Primo de Rivera, y los diversos ministros de finanzas: Wais, Prieto, Lara y Rico Avello (pp. 137-138).

Por supuesto que en la República Argentina se produciría un gran debate político y partidario. Como indica el autor, entre las décadas de 1920 y 1930 se produjo un elevado número de discusiones y críticas sobre los aspectos legales y económicos de las concesiones eléctricas. Partidos como el de la Unión Cívica Radical, el Socialista, el Demócrata Progresista, o hasta los sindicatos obreros, levantaron su voz, acompañaron la crisis internacional de 1929. Tema que Mónica Quijada abordó en 1991 con su libro Aires de República, aire de Cruzada. La Guerra Civil española en Argentina (Barcelona, Sendas Ediciones), mostrándonos ya entonces la trascendencia de esos momentos históricos que forzarían también la transformación de las empresas españolas fuera de su frontera. De ahí las dos explicaciones que aparecen en el capítulo cuatro de Borja, sobre los conflictos con los usuarios establecidos en la ciudad de Buenos Aires, y en el quinto, sobre la argentinización de la CHADE como "solución" ante la Guerra Civil que iniciara el ejército liderado por Francisco Franco contra la Segunda República española. Entre los personajes más dedicados a esta transformación, el autor cita a Rafael Vehils i Grau-Bolívar, establecido en 
Buenos Aires hasta su muerte, como hiciera Cambó, o a Joan Ventosa i Calvell, el gran colaborador cuyas cartas son la gran base de análisis de Riquer.

Los siguientes capítulos muestran la visión que generó la nueva empresa, ahora argentina: Compañía Argentina de Electricidad (CADE). El número siete se centra en las denuncias, gastos confidenciales y convenios secretos que tuvieron lugar de la mano de gobiernos y empresarios vinculados a la antigua CHADE, y el propio gobierno argentino. El octavo se centra en la ingeniería financiera y la fuga de capitales que sigue siendo hasta hoy día uno de los elementos más vinculados a la propia historia argentina. El noveno sobre la constitución de la Comisión Investigadora Rodríguez Conde entre el golpe de Estado de 1943 y el acceso al poder de Juan Domingo Perón.

Los últimos cuatro capítulos de la obra se centran en el peligro que sufre la CADE ante estas demandas políticas, económicas y sociales; la unión producida entre los imputados Cambó, Ventosa y Heineman para salvaguardar el control de la electricidad de las antiguas colonias españolas; el gran privilegio que otorga entonces el militar Perón, elegido como presidente para facilitar su acceso en 1946 de la mano de su esposa, Eva Duarte; el papel ejercido por el gobierno franquista para liquidar la CHADE; y finalmente el triunfo de la CADE y de SOFINA para sostener el capital, despojando de la presidencia al argentino Arturo Frondizi, hecho producido entre los años 1955 y 1959 junto al crecimiento indiscutible, y sin control, del Fondo Monetario Internacional (FMI).

Por ello, Borja de Riquer i Permanyer cierra este interesante libro con una simple conclusión dedicada a la corrupción y al ejercicio efectuado por los corrompidos. Los cambios de la CATE, la CHADE y la CADE han formado parte de esta ineludible putrefacción que fue acompañada por la SOFINA. Para el autor, "no hay duda que la oscura y compleja historia de la CHADE, la gran empresa que presidió Cambó durante casi tres décadas, no fue nada ejemplar" (p. 536). Cambó terminó instalándose en Argentina, donde murió en 1947, el año en que estaba dispuesto a viajar a España y negociar con Francisco Franco. Su gran secretario, Rafael Vehils, murió una década después, en el mismo día de su nacimiento, dejando a su único hijo como miembro de las relaciones internacionales. Jorge Alberto Rafael Vehils Balléry, así llamado, fue enviado como cónsul argentino y embajador extraordinario y plenipotenciario de la Argentina, pero en un territorio totalmente desconocido y poco importante: la República Federal de Nigeria. Falleció en Buenos Aires el 26 de agosto de 2011, después de comentar que fue su propio padre quien se encargó en su momento de entregar importantes sobres con dinero para los diputados argentinos. Ante cosas como estas, Riquer nos plantea la complejidad de la elaboración de un estudio, completo y riguroso, sobre la vida de Cambó.

El conservadurismo político de Francesc Cambó es parte de la propia historia de la política catalana. Pero la gran contribución que hace el catedrático emérito de Historia Contemporánea en la Universidad Autónoma de Barcelona (UAB), 
es dejar una mirada, dentro de la propia Barcelona, de la contribución empresarial, financiera y gubernamental de Cambó a través de la CATE, la CHADE y la CADE, pasando así, teóricamente, entre Alemania, España (Cataluña) y Argentina. Lo compleja y polémica que fue la vida de Cambó, otorga un entorno de análisis: para Borja, "se trata de otra cara, de una faceta, que habrá que añadir a las más conocidas de Cambó como destacado líder del catalanismo conservador, como hábil hombre de estado y como destacado mecenas de la cultura catalana" (p. 535). 